\title{
External validity of somatostatin analogues trials in advanced neuroendocrine neoplasms: the GETNE- TRASGU study
}

DOI:

10.1159/000514808

\section{Document Version}

Accepted author manuscript

Link to publication record in Manchester Research Explorer

Citation for published version (APA):

Jimenez-fonseca, P., Carmona-bayonas, A., Lamarca, A., Barriuso, J., Castaño, A., Benavent, M., Alonso, V., Riesco, M. D. C., Alonso-gordoa, T., Custodio, A., Sanchez Canovas, M., Hernando, J., López, C., La Casta, A., Fernandez Montes, A., Marazuela, M., Crespo, G., Diaz, J. A., Feliciangeli, E., ... Garcia-carbonero, R. (2021). External validity of somatostatin analogues trials in advanced neuroendocrine neoplasms: the GETNE-TRASGU study. Neuroendocrinology, 0, [0]. https://doi.org/10.1159/000514808

Published in:

Neuroendocrinology

\section{Citing this paper}

Please note that where the full-text provided on Manchester Research Explorer is the Author Accepted Manuscript or Proof version this may differ from the final Published version. If citing, it is advised that you check and use the publisher's definitive version.

\section{General rights}

Copyright and moral rights for the publications made accessible in the Research Explorer are retained by the authors and/or other copyright owners and it is a condition of accessing publications that users recognise and abide by the legal requirements associated with these rights.

\section{Takedown policy}

If you believe that this document breaches copyright please refer to the University of Manchester's Takedown Procedures [http://man.ac.uk/04Y6Bo] or contact uml.scholarlycommunications@manchester.ac.uk providing relevant details, so we can investigate your claim.

\section{OPEN ACCESS}




\section{Neuroendocrinology}

DOI: $10.1159 / 000514808$

Received: 10/30/2020

Accepted: $1 / 27 / 2021$

Published(online): 1/28/2021

External validity of somatostatin analogues trials in advanced neuroendocrine neoplasms:

the GETNE-TRASGU study

Jimenez-Fonseca P. Carmona-Bayonas A. Lamarca A. Barriuso J. Castaño Á. Benavent M. Alonso

V. Riesco M.C. Alonso-Gordoa T. Custodio A. Sanchez Canovas M. Hernando J. López C. La

Casta A. Fernandez Montes A. Marazuela M. Crespo G. Diaz J.A. Feliciangeli E. Gallego J.

Llanos M. Segura A. Vilardell F. Percovich J.C. Grande E. Capdevila J. Valle J. Garcia-

Carbonero R.

ISSN: 0028-3835 (Print), elSSN: 1423-0194 (Online)

https://www.karger.com/NEN

Neuroendocrinology

\section{Disclaimer:}

Accepted, unedited article not yet assigned to an issue. The statements, opinions and data contained in this publication are solely those of the individual authors and contributors and not of the publisher and the editor(s). The publisher and the editor(s) disclaim responsibility for any injury to persons or property resulting from any ideas, methods, instructions or products referred to in the content.

\section{Copyright:}

All rights reserved. No part of this publication may be translated into other languages, reproduced or utilized in any form or by any means, electronic or mechanical, including photocopying, recording, microcopying, or by any information storage and retrieval system, without permission in writing from the publisher.

(C) 2021 S. Karger AG, Basel 


\section{Research article}

Manuscript title: External validity of somatostatin analogues trials in advanced neuroendocrine neoplasms: the GETNE-TRASGU study

Authors: Paula Jimenez-Fonseca ${ }^{a^{*}}$, Alberto Carmona-Bayonas ${ }^{b^{*}}$, Angela Lamarca ${ }^{c, d}$, Jorge Barriuso $^{\mathrm{c}, \mathrm{d}}$, Angel Castaño $^{\mathrm{e}}$, Marta Benavent ${ }^{\dagger}$, Vicente Alonso ${ }^{g}$, Maria del Carmen Riesco ${ }^{h}$, Teresa Alonso-Gordoa', Ana Custodioj, Manuel Sanchez Canovas ${ }^{b}$, Jorge Hernando ${ }^{k}$, Carlos López', Adelaida La Casta ${ }^{m}$, Ana Fernandez Montes ${ }^{n}$, Mónica Marazuela ${ }^{\circ}$, Guillermo Crespo ${ }^{p}$, Jose Angel Diaz ${ }^{q}$, Eduardo Feliciangelir, Javier Gallegos, Marta Llanos ${ }^{\dagger}$, Angel Segura ${ }^{u}$, Felip Vilardell ${ }^{\mathrm{v}}$, Juan Carlos Percovich ${ }^{\mathrm{w}}$, Enrique Grande ${ }^{\mathrm{x}}$, Jaume Capdevila ${ }^{\mathrm{k}}$, Juan Valle ${ }^{\mathrm{c}, \mathrm{d}}$, Rocio Garcia-Carbonero ${ }^{\mathrm{h}}$

\section{Affiliations:}

a. Medical Oncology Department, Hospital Universitario Central de Asturias, ISPA, Oviedo, Spain

b. Hematology and Medical Oncology Department, Hospital Universitario Morales Meseguer, UMU, IMIB, Murcia, Spain

c. Medical Oncology Department, The Christie NHS Foundation Trust, ENETS Centre of Excellence, Manchester, United Kingdom

d. Division of Cancer Sciences, Faculty of Biology Medicine and Health, University of Manchester, Manchester, United Kingdom

e. Pathology Department, Hospital Universitario de Fuenlabrada, Madrid, Spain

f. Medical Oncology Department, Hospital Universitario Virgen del Rocío, Instituto de Biomedicina de Sevilla (IBIS), Sevilla, Spain

g. Medical Oncology Department, Hospital Universitario Miguel Servet, Zaragoza, Spain

h. Medical Oncology Department, Hospital Universitario Doce de Octubre, IIS imas12, UCM, CNIO, CIBERONC, Madrid, Spain

i. Medical Oncology Department, Hospital Universitario Ramón y Cajal, Madrid, Spain

j. Medical Oncology Department, Hospital Universitario La Paz, CIBERONC CB16/12/00398, Madrid, Spain

k. Medical Oncology Department, Hospital Universitario Vall d'Hebron, Vall Hebron Institute of Oncology (VHIO), Autonomous University of Barcelona, Barcelona, Spain

I. Medical Oncology Department, Hospital Universitario Marqués de Valdecilla, IDIVAL, Santander, Spain

m. Medical Oncology Department, Hospital Universitario Donostia, San Sebastián, Spain

n. Medical Oncology Department, Complexo Hospitalario Universitario de Ourense, Orense, Spain

o. Endocrinology Department, Hospital Universitario de la Princesa, Madrid, Spain

p. Medical Oncology Department, Complejo Asistencial Universitario de Burgos, Burgos, Spain

q. Endocrinology Department, Hospital Universitario Clínico San Carlos, Madrid, Spain

r. Medical Oncology Department, Hospital Universitario Santa Lucia, Cartagena, Spain

s. Medical Oncology Department, Hospital General Universitario de Elche, Elche, Spain

t. Medical Oncology Department, Hospital Universitario de Canarias, Universidad de La Laguna, Tenerife, Spain

u. Medical Oncology Department, Hospital Universitario La Fe, Valencia, Spain

v. Pathology Department, Hospital Universitari Arnau de Vilanova, Lleida, Spain

w. Endocrinology Department, Hospital Universitario Gregorio Marañon, Madrid, Spain

x. Medical Oncology Department, MD Anderson Cancer Center Madrid, Madrid, Spain

${ }^{*}$ These authors contributed equally to this work.

Short Title: External validity of somatostatin analogues trials in neuroendocrine tumors

\section{Corresponding author:}

Paula Jimenez-Fonseca

Medical Oncology Department 
Hospital Universitario Central de Asturias

Avenida de Roma, sn,

Oviedo, 33011, Spain.

Telephone: +34985106121

E-mail: palucaji@hotmail.com

Keywords: Bayesian method, lanreotide, neuroendocrine tumor, octreotide, survival, somatostatin analogue.

Number of Tables: 3

Number of Figures: 6

Word count: 2725 


\section{ABSTRACT}

Introduction: Somatostatin analogues (SSA) prolong progression-free survival (PFS) in patients with well-differentiated gastroenteropancreatic neuroendocrine neoplasms (GEP-NENs). However, the eligibility criteria in randomized clinical trials (RCTs) have been restricted, which contrasts with the vast heterogeneity found in NENs.

Methods: We identified patients with well-differentiated (Ki67\% $\leq 20 \%$ ), metastatic GEP-NENs treated in first-line with SSA monotherapy from the Spanish R-GETNE registry. The therapeutic effect was evaluated using a Bayesian Cox model. The objective was to compare survival-based outcomes from real world clinical practice versus RCTs.

Results: The dataset contained 535 patients with a median age of 62 years (range: 26-89). The median Ki67\% was 4 (range: 0-20). The most common primary tumor sites were: midgut, 46\%; pancreas, 34\%; unknown primary, 10\%; and colorectal, $10 \%$. Half of the patients received octreotide LAR $(n=266)$ and half, lanreotide autogel $(n=269)$. The median PFS was 28.0 months (95\% Cl, 22.1-32.0) for octreotide vs 30.1 months (95\% Cl, 23.1-38.0) for lanreotide. The overall hazard ratio for lanreotide vs octreotide was 0.90 (95\% credible interval, $0.71-1.12)$. The probability of effect sizes $>30 \%$ with lanreotide vs octreotide was $2 \%$ and $6 \%$ for midgut and foregut NENs, respectively.

Conclusion: Our study evaluated the external validity of RCTs examining SSAs in the real world, as well as the main effect-modifying factors (progression status, symptoms, tumor site, specific metastases, and analytical data). Our results indicate that both octreotide LAR and lanreotide autogel had a similar effect on PFS. Consequently, both represent valid alternatives in patients with well-differentiated, metastatic GEP-NENs. 


\section{Introduction}

Somatostatin is a hormonal peptide that naturally inhibits endocrine and exocrine secretion. In neuroendocrine neoplasms (NENs), somatostatin slows tumor growth and has antiproliferative, antiangiogenic, and proapoptoic effects [1]. Somatostatin acts through a family of G-proteincoupled receptors, five subtypes of which are known (SSTR1-SSTR5); their activation brings about a complex intracellular cascade [2]. Given that, most gastroenteropancreatic NENs (GEPNENs) express several SST receptors (SSTR) isoforms, synthetic somatostatin analogues (SSAs) have been developed with antisecretory and antiproliferative effects.

Octreotide LAR and lanreotide autogel are the only SSAs currently available that have proven their efficacy in randomized-controlled trials (RCTs) with progression-free survival (PFS) as their primary end-point $[3,4]$. However, evidence continues to be relatively scant, given that these RCTs, in addition to having small sample sizes, have applied restricted eligibility criteria, in stark contrast with the tremendous clinical and molecular heterogeneity exhibited by NENs. In the PROMID study, 85 German patients with advanced NENs of midgut origin and Ki-67 values of up to $2 \%(95 \%)$ were randomized to receive octreotide LAR $30 \mathrm{mg}$ or placebo every 4 weeks [3]. While the octreotide LAR-treated participants had a longer PFS (14.3 vs 6 months, $P<0.001$ ), this population is by no means representative. Thus, barely $16 \%$ of the Spanish National Cancer Registry (R-GETNE) sample would have met these selection criteria [5]. More recently, the CLARINET trial randomized 204 patients with advanced, Ki-67 $<10 \%$, non-functioning, SSTRpositive NENs to lanreotide autogel $120 \mathrm{mg}$ or placebo every 4 weeks [4]. This sample was greater, insofar as the trial enrolled subjects with NENs of pancreatic, midgut, hindgut, or unknown origin. Treatment with lanreotide autogel significantly prolonged PFS (median not reached vs 18 months, respectively, $\mathrm{p}=0.0002$ ). Nevertheless, it is crucial that we bear in mind that $96 \%$ had documented stable disease, which happens in $<10 \%$ of the individuals when deciding on treatment [6]. Moreover, $68 \%$ of the NENs were Ki-67 $\leq 2 \%$, while in the real world, this group comprises approximately one quarter of the tumors [7]. Despite the fact that CLARINET is a larger RCT, given the variability of tumor sites, each of the strata comprises very few patients (e.g., the inference regarding hindgut tumors is based on 14 individuals). Therefore, 
the statistical evidence was limited for pancreatic (hazard ratio $[H R]=0.58 ; 95 \%$ confidence interval $[\mathrm{Cl}], 0.32-1.04)$ or hindgut NENs $(\mathrm{HR}=1.47 ; 95 \% \mathrm{Cl}, 0.16-13.24)$, which could be due to the small size of these subgroups.

When all the SSA RCTs are pooled, the scant representativity of certain tumor subtypes is conspicuous, such as grade 2 NENs, extraintestinal tumors, or those in progression, pointing to the need to ascertain the external validity of these RCTs with real world evidence (RWE). External validity is a broad construct that refers to the ability to generalize the inference of the RCTs, extrapolating trial outcomes from one population to another $[8,9]$. The concept is not purely statistical; instead, it covers a whole series of determinants that include eligibility criteria, pathological traits, access to new therapies, geographic disparity, etc. Given the changing conditions of clinical practice and the target population, it is fitting that a revision of the inferential generalizability of past RCTs be undertaken from time to time [9-12]. This notion is particularly germane in this case, given the paucity of data regarding effect-modifying factors $[6,13]$.

In addition to these gaps in knowledge, there is the fact that no RCT has directly compared the anti-tumor effect of both SSAs and it is unlikely that such a study will materialize in the immediate future. Although both SSAs target SSTR2, exhibiting lower affinity for SSTR5, relevant differences between both drugs may potentially influence their antiproliferative activity, including different affinities for the receptor, their ability to stabilize their active conformations, drug formulation, administration route, pharmacokinetics, bioavailability, and the different antiproliferative doses. As for endocrine secretion control, a small crossover trial found that lanreotide autogel and octreotide LAR appeared equally effective in alleviating carcinoid syndrome, inducing similar reductions of urinary 5-hydroxyindole acetic acid (5-HIAA) and plasma serotonin [14]. However, as for their antiproliferative effects, caution must be exercised when assuming bioequivalence by virtue of molecular similarities, and the relative sensitivity of individual GEP-NET subtypes to a particular SSA has yet to be elucidated [15].

Our study sought to shed light on these vital issues. Accordingly, we endeavored to explore the trend observed in RCTs in a national registry of GEP-NENs (R-GETNE) with the aim of 
contrasting RCTs with a broader and contextually rich series, as well as to evaluate the differential effect of octreotide LAR vs lanreotide autogel on PFS.

\section{Materials and Methods}

\section{Patients}

Participants were from the hospital-based National Cancer Registry (R-GETNE) (data cut-off date for analyses: December 2018) with the participation of 74 Spanish centers and The Christie NHS Foundation Trust, ENETS Centre of Excellence, Manchester, United Kingdom. Patients initiated therapy between 2002 and 2017. The design, characteristics, and quality criteria of this registry have been previously reported [5,6,16-18]. Data from a total of 4,068 available cases were screened for eligibility and additional quality controls were implemented for this analysis (doublechecking of data, monitoring of discrepancies, and unjustified missing data).

Eligibility criteria for this sub-study included: (1) presence of advanced disease measurable by RECIST v1.1 that had been monitored by computed tomography (CT) at least every 3-6 months until documentation of disease progression [19], (2) histologically-confirmed GEP-NEN, (3) welldifferentiated tumor as per the WHO 2010 classification with Ki-67 $\leq 20 \%$ [20], and (4) use of SSA (lanreotide autogel or octreotide LAR) in monotherapy, as first-line antiproliferative treatment, with the intention of disease control until radiological progression. Patients were excluded if they received other concurrent systemic therapies, underwent surgery for metastases, or had inadequate documentation (preventing effective analysis of clinical information). All consecutive cases meeting these eligibility criteria, without any subsequent sample matching, were selected. The flow-chart reflecting the selection process can be found in Annex Fig. 1.

\section{Objectives \& variables of interest}

The primary endpoint of this study was PFS, defined as the period of time between initiation of SSA treatment and tumor progression or death due to any cause, censoring individuals with no event at last follow-up. The main objective was to compare survival-based outcomes from real world clinical practice versus RCTs. Other objectives were to explore the potential 
appropriateness of PFS as a surrogate endpoint for overall survival (OS), and to compare the treatment effect of lanreotide autogel vs octreotide LAR on PFS, which was designed as an exploratory objective, interpretable as a hypothesis generator.

In this non-randomized study, confounding factors were chosen after reviewing the literature and consulting the Spanish Taskforce Group of Neuroendocrine Tumors (GETNE) experts, in such a way that all variables potentially involved in prognosis and treatment selection were taken into account. Thus, in order to adjust for the differential effect of the SSAs, patient (age, gender, Eastern Cooperative Oncology Group Performance Status [ECOG-PS]), tumor (primary tumor site, Ki-67\%, histological differentiation, hepatic tumor burden, peritoneal metastases, bone metastases, documented progression status prior to initiating SSA [tumor progression vs stable disease not documented or $<3$ months, vs stable disease $\geq 3$ months], symptoms), laboratory (alkaline phosphatase, neutrophil-lymphocyte ratio [NLR], hemoglobin, platelets), and treatmentrelated variables (year initiated, dosage) were taken into consideration.

Given the small number of patients in each specific location, tumors were grouped into three subgroups for analysis: foregut (stomach, pancreas), midgut (duodenum, jejunum, ileum, appendix, ascending colon), and hindgut (descending and sigmoid colon, and rectum) [4].

\section{Statistical analysis}

Therapeutic effects were evaluated by means of Bayesian Cox models. A detailed justification of the advantages of Bayesian models, as well as their interpretation, have been extensively described by several authors [21-25]. In particular, instead of null hypothesis significance testing, the intention was to estimate the actual probability of benefit in favor of one of the drugs [22]. Acknowledging the absence of previously published information, a weakly informative prior was applied for the therapeutic effect, and covariates: $\sim N(0,10)$. Considering the rationale of this research (see above), subgroup effects were explored with moderate skeptic priors on all interactions $\sim \mathrm{N}(0,0.5)$.

To measure convergence, we used trace plots for Markov Chain Monte Carlo (MCMC) sample and Gelman-Rubin convergence measurement (Rhat) for all variables, denoting adequate 
convergence (Rhat $<1.1$ for all parameters, see Annex Figure 2). Covariates with $>20 \%$ missing values were discarded. Multiple imputation by chained equations was used in the remainder variables. In no case were data-driven methods used to select covariates (see above). Continuous variables were evaluated using restricted cubic splines. Correlation between PFS and OS was computed by means of Kendall's T associated with Clayton's copula models for bivariate survival data. Analyses were performed with the R software package v3.1.6, with mice, splines, bayestestR, rms, brms, and rstanarm packages [26-28]. To visualize certain effects, interactive graphics have been generated with the Plotly R graphing library [29].

\section{RESULTS}

\section{Patients}

A total of 535 consecutive, eligible patients were included. Table 1 displays the baseline characteristics of these patients. One-half received lanreotide autogel $(n=269)$ and the other half, octreotide LAR ( $n=266)$. A median of 21 doses were administered (range 1-168). Treatment was started at the usual recommended dose in $80 \%$ (octreotide LAR, $30 \mathrm{mg}$ ) and $86 \%$ (lanreotide autogel, $120 \mathrm{mg}$ every 4 weeks) of patients. Dosage was increased in $14 \%$ during follow-up and reduced in $0 \%$; only $3.6 \%$ interrupted therapy for more than 1 month during treatment. The clinico-pathological characteristics were similar for both SSAs. The use of lanreotide autogel has increased over time ( $72 \%$ of SSAs used from 2016 onward). At the time of analysis, 350 progression events and 228 of death were reported, with a median PFS of 27.6 months (95\% Cl, 23.5-30.7) and median OS of 85.9 months (95\% Cl, 71.5-96.6) (Fig. 1). Death without radiological confirmation of progression occurred in 19 patients (14 with lanreotide autogel, 5 with Sandostatin LAR).

PFS correlated modestly with OS (Kendall's $\mathrm{T}=0.553$, standard error [SE] $=0.027$ ). Both SSAs, lanreotide vs octreotide, were well tolerated with diarrhea being the most frequent toxicity $(20.2 \%$ vs $20.0 \%$, respectively); serious adverse events were infrequent with cholelithiasis being the most common (7.2 vs $10.2 \%$, respectively) (Table 2 ). 


\section{Comparison of octreotide LAR and lanreotide autogel}

At the time of analysis, 159 progression and 103 death events had been detected in the lanreotide autogel group, compared to 191 progression and 125 death events with octreotide LAR. The median PFS and OS for lanreotide autogel vs octreotide LAR were 28.6 months (95\% $\mathrm{Cl}, 23.2-31.1)$ vs $27.3(95 \% \mathrm{Cl}, 20.9-31.1)$, and 85.0 months $(95 \% \mathrm{Cl}, 65.5-103.4)$ vs 85.9 (95\% $\mathrm{Cl}, 70.1-96.6)$, respectively (see global PFS data in interactive graph).

The overall HR for lanreotide was 0.90 (95\% credible interval [Crl], 0.71-1.12). The probability that this parameter was in the region of practical equivalence (ROPE, corresponding to $H R=1,+/-$ 0.1 ) was $48 \%$ (see density plots in Fig. 2). The posterior probability that the therapeutic effect of lanreotide exceeded that of octreotide by more than $15 \%$ and $30 \%(\mathrm{HR}<0.85$ and $<0.7)$ was $31 \%$ and $2 \%$, respectively. In the frequentist Cox model, the effect size was comparable $(H R=1.03$, 95\% Cl, 0.81-1.32, p=0.792) (Fig. 3).

Therapeutic effect was estimated in the subgroup with a positive octreotide scan in a sensitivity analysis; no substantial variations were revealed ( $\mathrm{HR}$ for progression of $0.98,95 \% \mathrm{Cl}, 0.77-1.24$ ). Median PFS was 29.2 months $(95 \% \mathrm{Cl}, 24.9-31.8)$ if the octreotide scan was positive, versus 19.4 months $(95 \% \mathrm{Cl}, 15.7-29.8)$ if an octreotide scan had not been performed (log-rank, $\mathrm{p}$ value=0.06).

\section{Conditional effects}

Figures 4 and 5 illustrate the PFS/OS Kaplan-Meier curves for the different tumor locations. For lanreotide autogel, PFS medians were 20.3, 42.4, and 47.9 months for foregut, midgut, and hindgut tumors, respectively. Similarly, PFS medians were 22.2, 41.9, and 18.4 months in the case of octreotide LAR, in the same strata. Depending on the primary tumor site, the Bayesian probability of a $\mathrm{HR}<0.70$ in favor of lanreotide was $6 \%, 2 \%, 37 \%$ and $47 \%$ for foregut, midgut, hindgut and tumors of unknown origin, respectively.

The remaining conditional effects are summarized in Table 3. Among these, the probability of effect size $>30 \%$ in favor of lanreotide $(\mathrm{HR}<0.70)$ was $76 \%$ for those patients with prior stable disease for more than three months at time of SSA initiation. 
The interaction between the therapeutic effect and Ki67 was also explored using a Cox frequentist model (see interactive graph); nevertheless, the statistical support in favor of the interactions was modest. The effectiveness of both SSAs was stable over the years (Fig. 6).

\section{DISCUSSION}

With this study, we have updated the external validity of the international bibliography as regards first-line SSA treatment for advanced GEP-NENs [3,4]. Overall, our data reveal substantial similarities and differences with respect to previous RCTs. Thus, the median PFS we detected in the lanreotide autogel-treated group (28.6 months) is consistent with long-term follow-up reports of the CLARINET RCT (30.8 months in a post hoc analysis) [30,31]. When broken down by tumor type, discreet differences are found in the median PFS in the CLARINET trial (29.7 and 61.5 months for foregut and midgut tumors) versus our series (20.3 and 42.4 months) [32]. Conversely, the median OS here is approximately seven years, and it was not reached after 9.2 years of follow-up in the CLARINET study [31]. As for the PROMID trial, our OS data are comparable (median of 84.7 vs 85.9 months). The most sizable difference is the shorter median PFS in the PROMID trial (14.3 months) relative to our data (41.9 months in midgut tumors), which is congruent with data reported by other authors [33,34]. All this indicates that PFS varies depending on the tumor type, which must be considered when comparing studies. Thus, the favorable PFS and OS in the CLARINET study is linked to the good baseline prognosis of the sample, i.e., enriched with stable, grade 1 NENs.

Contrary to the longer time-to-event reported in the CLARINET study, our data point toward a scant probability that either SSA can be associated with a substantial increase in PFS in patients with foregut and midgut NENs. This conclusion would support the pharmacokinetic similarities of both drugs, their comparable affinity profile for SSTR2 and SSTR5 [15,35], apparent equivalence on symptomatic control, similar reduction of biochemical markers in patients with both carcinoid syndrome and acromegaly [14,36-40], and similar antiproliferative effect [41]. Therefore, the different results between the two studies are probably due to the composition of the samples. 
Assessing therapeutic equivalence could be more complex, given that SSTR2 and SSTR5 distribution and density vary and are often low for effective biological interaction. Thus, pharmacodynamic aspects could be crucial. While octreotide has more in vitro affinity for SSTR2 and SSTR5 than lanreotide autogel $[15,35]$, this does not translate directly to SSA activity, given the different formulations of both drugs. In fact, the most effective antiproliferative doses have scantly been studied and have instead, been merely extrapolated from their antisecretory effects [42]. Additionally, several studies have shown that SSTR2 and SSTR5 are expressed heterogeneously in different tumor sites and depending on the degree of differentiation [43-45], with potential clinical and prognostic impact $[43,44]$.

Therefore, pancreatic NENs express more SSTR2 than gastrointestinal NENs [44]. Similarly, studies with 111 Indium-DOTA-[Tyr3]-octreotide (111/n-DOTA-TOC) suggest lower receptor density in hindgut NENs [46]. Tumors with lower SSTR2 and SSTR5 density may require adapted doses. Likewise, in patients with acromegaly, it has been speculated that titrated doses of SSAs are more effective than fixed doses [47,48]. Although data are limited, high doses or switching between SSAs is sometimes effective in clinical practice after progression to antiproliferative doses $[13,49]$ which would appear to endorse this hypothesis.

Lanreotide autogel and Sandostatin LAR have different approved indications. Both the Food and Drug Administration (FDA) and the European Medicines Agency (EMA) have approved lanreotide autogel as an antiproliferative treatment for grade 1-2 GEP-NENs, while Sandostatin LAR was approved by EMA for midgut or unknown primary tumors, or as a symptomatic therapy. Still, both are prescribed off-label interchangeably, as demonstrated by the similarity of use in this registry. With this in mind, our study has sought to explore the anti-proliferative effects as a function of the primary tumor site.

Our results replicate the trends observed in RCTs and suggest that octreotide LAR and lanreotide autogel are equally effective in foregut (pancreas and stomach) and midgut NENs (small bowel, appendix and right colon). Colonic NENs deserve additional attention; in our series, right colon NENs had a prognosis comparable to all other midgut NENs, while tumors originating in the left colon and rectum (hindgut) were the most aggressive [6]. The few existing data in the literature 
indicate that hindgut NENs have a somewhat different molecular biology and SSTR expression pattern $[50,51]$; hence, they might respond differently to therapy. In fact, the EMA excluded all colorectal NENs from the indication for lanreotide autogel, due to lack of evidence in the CLARINET study $(\mathrm{HR}=1.47,95 \% \mathrm{Cl}$ 0.16-13.24) [52]. In contrast, our data support SSA treatment for right colorectal tumors, taking into consideration the factors that predict benefit [6]. In interpreting the results, it is also important to note that the endpoint currently considered clinically relevant (i.e., PFS), depends on radiological progression according to morphological criteria (RECIST). This entails certain limitations in NENs, as functional differences are not factored in [18]. For its part, PFS is deemed an acceptable surrogate endpoint for OS in RCTs of NENs [53]. Nonetheless, there is little information specific for SSA-treated patients, and Imaoka et al's analysis points to a substantially lower correlation in this context, probably because tumors treated in first-line with SSAs are indolent and have multiple possibilities of subsequent therapies [53]. Our data coincide with Imaoka's in that the correlation of PFS and OS is modest, with no relevant variations in OS estimates.

Moreover, to the extent that PFS differences between the two SSAs are small and the molecules are similar, the local pharmacoeconomic context should be considered as another relevant aspect in the treatment decision $[54,55]$. However, variability in cost between different countries and the imminent introduction of biosimilars makes such analysis challenging.

Certain limitations to this study are worth highlighting. One is the retrospective nature of the database, although all information in R-GETNE was double-checked and inconsistencies were monitored in both cohorts. While the series comprises patients treated from 2000 onwards, our analysis denotes that the propensity to declare progression has not changed, nor have differential effects been substantially diluted over the years. However, this must be taken into account in the interpretation of the analysis. Second, subgroup analyses have obvious limitations, such as low statistical power and uncertainty when the subject falls into subgroups that reveal opposite effects, leading to possibly spurious inferences [56]. Third, this is a non-randomized study and although multivariable models have contemplated the most important covariates in NENs, the presence of residual confounding bias in favor of lanreotide autogel cannot be ruled out, 
particularly in the case of stable or hindgut NENs. Fourth, although no intervention was made on the timing of the CT-scans, an evaluation by RECIST v1.1 was required at least every 6 months, in the absence of any suspicion of a different time pattern for each therapy. Therefore, as for interpretation, these results should be considered as hypothesis-generators, and aspire to stimulate the development of rigorous RCTs and expand the information available on minority subgroups, particularly hindgut NENs. Finally, the reader should understand that all subjects in this series received first-line treatment with SSA in monotherapy. Inasmuch as the results uphold the absence of substantial differences between drugs, the design does not enable inferences to be made about different strategies, such as combinations or watch and wait.

In conclusion, our data confirm the applicability of the results of the RCTs of SSAs in GEP-NETs in a real-world registry. Nevertheless, the outcomes were slightly worse compared to the CLARINET study, albeit better in terms of PFS with respect to PROMID. To probe further into the reasons for these apparent discrepancies between trials and compared to a real-world series, we took the most significant effect-modifying factors into account. This is indispensable, given the biological diversity of this pathology. Our data suggest that both SSAs have approximately equivalent efficacy, at least in pancreatic and midgut NETs and are, therefore, acceptable alternatives in most situations. With these data in hand, there is a compelling need to design new RCTs in NETs that separate out the evaluation of effects based on clinical-pathological variables, with hindgut tumors being a clear priority area for future research. 


\section{Statements}

\section{Acknowledgements}

We are grateful to GETNE for sponsoring this study and generating the necessary network for this collaborative work, and the MFAR S.L. team for the support of the website registry. We would like to thank Priscilla Chase Duran for editing and translating the manuscript.

\section{Statement of Ethics}

All procedures followed were in accordance with the ethical standards of the responsible committee on human research (institutional and national) and with the Helsinki Declaration of 1964 and later versions. R-GETNE was approved by the Research Ethics Committee of reference (Principality of Asturias, № 107/15, 30/07/2017), the Research Ethics Committee of each participating hospital, and by the Spanish Agency of Medicines and Medical Devices (AEMPS) (12/12/2014).

Informed consent (if applicable depending on the participating institution) was obtained from patients before they were included in the study.

\section{Conflict of Interest Statement}

PJF declares travel grants from Ipsen and consulting/advisory role for Roche, Celgene, Bristol, Mylan, Rovi, LEO Pharma, all outside of the scope of this work. ACB declares travel grants from Ipsen, Roche and Novartis and consulting/advisory role for Roche, Rovi, LEO Pharma, Pfizer, Esteve all outside of the scope of this work. AL has received travel and educational support from Ipsen, Pfizer, Bayer, Advanced Accelerator Applications (AAA), SirtEx, Novartis, Mylan and Delcath; speaker honoraria from Merck, Pfizer, Ipsen and Incyte; advisory honoraria from EISAI, Nutricia, Ipsen, QED and Roche; she is also a member of the Knowledge Network and NETConnect Initiatives funded by Ipsen. JB has received travel research and educational support from Ipsen, Pfizer, AAA, Novartis and Nanostring; speaker honoraria from Novartis, Pfizer and Ipsen; advisory honoraria from Nutricia. VA declares advisory role from Amgen, Roche, Merck, Servier, Sanofi, Bayer, Ipsen, Novartis; travel accommodations from Roche, Merck, Novartis, Ipsen, Sanofi; personal fees from Amgen, Roche, Merck, Servier, Sanofi, Bayer, Ipsen, Novartis, AAA and nonfinancial support from Roche, Merck, Novartis, Ipsen, Sanofi. TAG declares advisory role, travel grants and research funding from IPSEN, Novartis, Roche, BMS, Pfizer, Sanofi, Janssen, Astellas, Astrazeneca. MSC has received honoraria for advisory role from KyowaKirin, research funding from Leo Pharma, travel accommodations from Sanofi, MSD, Esteve, Amgen, Servier, Angelini, financial support for educational programs from Angelini, Sanofi, Rovi. JH declares speakers' bureau for Eisai, Ipsen, Roche, Angelini Pharma; travel, accommodations and expenses for Ipsen, Novartis, AAA, Roche, AstraZeneca and Eisai. CL has received honoraria from Roche, Merck, Sanofi, Pfizer, Eisai, Ipsen, Bayer; consulting or advisory role from Amgen, Roche, Sanofi, Merck, Servier, Pfizer, Ipsen, Bayer, Eisai; research funding from Amgen, Roche, Merck, Sanofi, Bayer, Ipsen, Eisai, Celgene and travel accommodations from Roche, Pfizer, Merck. Servier, Amgen and Ipsen. ALC has received grants for meetings from: Roche, Novartis, Amgen, 
Celgene. AFM has received honoraria for advisory role from Sanofi, Amgen and for speaker bureau from Roche, Servier, Sanofi, Lilly, Celgene. MM has received honoraria for ad boards, meetings and/or lectures from Novartis, Ipsen and Pfizer. GC has received honoraria for ad boards, meetings and/or lectures from Pfizer, BMS, Ipsen, Roche, Eisai, MSD, Sanofi, Novartis, Bayer, Janssen and Astellas. PE declares honoraria for ad boards from Sanofi, Roche and Amgen; as speaker from Roche, Sanofi, Merck, Servier, Novartis, Ipsen and Amgen and travel, accommodations expenses from Roche, Sanofi, Merck and Novartis. JAD has received honoraria for advisory role from Ipsen. EF has received travel and educational grants from IPSEN, Roche, Merck-Serono, MSD and Servier and advisory role from Merck. JG has received travel grants from Amgen and Novartis and has received honoraria for scientific consultancy role from Amgen, Bayer, Ipsen, Lilly, Merck, Roche, Servier. ML has received honoraria for scientific consultancy role from Roche, Bristol, Servier, Ipsen, Sanofi, Eisai, Amgen. JCP has received honoraria for scientific consultancy role from Ipsen, Novartis, Novo Nordisk and Sanofi. EG has received honoraria for ad boards, meetings and/or lectures from Pfizer, BMS, IPSEN, Roche, Eisai, Eusa Pharma, MSD, Sanofi, AAA, Novartis, Pierre Fabre, Lexicon and Celgene and has received unrestricted research grants from Pfizer, Astra Zeneca, MTEM/Threshold, Roche, IPSEN and Lexicon. JC has received honoraria for scientific consultancy role from Novartis, Pfizer, Ipsen, Exelixis, Bayer, Eisai, AAA, Amgen, Sanofi and Merck and research support from Eisai, Novartis, Ipsen, Astrazeneca, Pfizer and AAA. JWV declares consulting or advisory role for Agios, AstraZeneca, Delcath Systems, Keocyt, Genoscience Pharma, Incyte, Ipsen, Merck, Mundipharma EDO, Novartis, PCI Biotech, Pfizer, Pieris Pharmaceuticals, QED and Wren Laboratories; speakers' bureau for Imaging Equipment Limited, Ipsen, Novartis, Nucana; and travel grants from Celgene and Nucana, all outside of the scope of this work. RGC declares having provided scientific advice and/or received honorarium from AAA, Amgen, Bayer, Ipsen, Lilly, Merck, MSD, Novartis, PharmaMar, Pfizer, Roche and Sanofi-Aventis, and has received research support from Pfizer, all outside the scope of this work. The rest of authors have nothing to declare.

\section{Funding Sources}

The study has been funded by a restricted grant from Novartis Farmacéutica, S.A. This entity has not contributed in the design of the study, analysis, interpretation of the results, drafting of the document, nor in the decision regarding publication. RGETNE and the GETNE group is partially funded by Ipsen, Novartis, Pfizer and AAA. Dr Angela Lamarca received funding from ASCO Conquer Cancer Foundation Young Investigator Award and The Christie Charity. Dr Jorge Barriuso received funding from the received funding from the ENETS Centre of Excellence Fellowship Grant Award.

\section{Author contributions}

A.C.B. and P.J.F developed the project, analyzed the data and drafted the manuscript. A.L. and J.B. contributed to generate the idea of the present manuscript. The other authors recruited patients and provided clinical information, comments, and improvements to the manuscript. All authors participated in the interpretation and discussion of data, and the critical review of the manuscript. 


\section{REFERENCES}

1. Bousquet C, Lasfargues C, Chalabi M, Billah SM, Susini C, Vezzosi D, et al. Current Scientific Rationale for the Use of Somatostatin Analogs and mTOR Inhibitors in Neuroendocrine Tumor Therapy. J Clin Endocrinol Metab [Internet]. 2012 Mar 1;97(3):727-37. Available from: https://doi.org/10.1210/jc.2011-2088

2. Theodoropoulou M, Stalla GK. Somatostatin receptors: from signaling to clinical practice. Front Neuroendocrinol [Internet]. 2013/07/18. 2013 Aug;34(3):228-52. Available from: https://www.ncbi.nlm.nih.gov/pubmed/23872332

3. Rinke A, Müller HH, Schade-Brittinger C, Klose KJ, Barth P, Wied M, et al. Placebo-controlled, double-blind, prospective, randomized study on the effect of octreotide LAR in the control of tumor growth in patients with metastatic neuroendocrine midgut tumors: A report from the PROMID study group. J Clin Oncol. 2009;27(28):4656-63.

4. $\quad$ Caplin M, Ruszniewski P, Pavel M, Cwikla J, Phan A, Raderer M, et al. A randomized, double-blind, placeboControlled study of Lanreotide Antiproliferative Response in patients with gastroenteropancreatic NeuroEndocrine Tumors (CLARINET). Eur J Cancer. 2011;47 Suppl 2:abstract 8961.

5. Nuñez-Valdovinos B, Carmona-Bayonas A, Jimenez-Fonseca P, Capdevila J, Castaño-Pascual Á, Benavent $M$, et al. Neuroendocrine Tumor Heterogeneity Adds Uncertainty to the World Health Organization 2010 Classification: Real-World Data from the Spanish Tumor Registry (R-GETNE). Oncologist. 2018;23(4):422-32.

6. Carmona-Bayonas A, Jiménez-Fonseca P, Lamarca Á, Barriuso J, Castaño A, Benavent M, et al. Prediction of Progression-Free Survival in Patients With Advanced, Well-Differentiated, Neuroendocrine Tumors Being Treated With a Somatostatin Analog: The GETNE-TRASGU Study. J Clin Oncol [Internet]. 2019/08/07. 2019 Oct 1;37(28):2571-80. Available from: https://www.ncbi.nlm.nih.gov/pubmed/31390276

7. Nuñez-Valdovinos B, Carmona-Bayonas A, Jimenez-Fonseca P, Capdevila J, Castaño-Pascual Á, Benavent $M$, et al. Neuroendocrine Tumor Heterogeneity Adds Uncertainty to the World Health Organization 2010 Classification: Real-World Data from the Spanish Tumor Registry (R-GETNE). Oncologist. 2018;23(4).

8. Rothwell PM. Commentary: External validity of results of randomized trials: disentangling a complex concept. Int J Epidemiol. 2010;39(1):94-6.

9. Jimenez-Fonseca P, Carmona-Bayonas A, de Castro EM, Custodio A, Pijaume CP, Hernandez R, et al. External validity of docetaxel triplet trials in advanced gastric cancer: are there patients who still benefit? Gastric Cancer. 2020;1-12.

10. Rothwell PM. External validity of randomised controlled trials:"to whom do the results of this trial apply?" Lancet. 2005;365(9453):82-93.

11. Royston P, Parmar MKB, Altman DG. External validation and updating of a prognostic survival model [Internet]. Vol. 17, Hub for Trials Methodology Research. 2010. Available from:

https://www.semanticscholar.org/paper/External-validation-and-updating-of-a-prognostic-1-RoystonParmar/5ba4a569ffa416f740a106e491560837074ce44b

12. Dekkers OM, Elm E von, Algra A, Romijn JA, Vandenbroucke JP. How to assess the external validity of therapeutic trials: a conceptual approach. Int J Epidemiol. 2010;39(1):89-94.

13. Carmona-Bayonas A, Jiménez-Fonseca P, Custodio A, Grande E, Capdevila J, López C, et al. Optimizing somatostatin analog use in well or moderately differentiated gastroenteropancreatic neuroendocrine tumors. Curr Oncol Rep. 2017;19(11):72.

14. O'Toole D, Ducreux M, Bommelaer G, Wemeau JL, Bouché O, Catus F, et al. Treatment of carcinoid syndrome: A prospective crossover evaluation of lanreotide versus octreotide in terms of efficacy, patient acceptability, and tolerance. Cancer. 2000;88(4):770-6.

15. Chalabi M, Duluc C, Caron P, Vezzosi D, Guillermet-Guibert J, Pyronnet S, et al. Somatostatin analogs: does pharmacology impact antitumor efficacy? Trends Endocrinol Metab [Internet]. 2014/01/07. 2014 Mar;25(3):115-27. Available from: https://www.ncbi.nlm.nih.gov/pubmed/24405892

16. Garcia-Carbonero R, Capdevila J, Crespo-Herrero G, Díaz-Pérez JA et al. Incidence, patterns of care and prognostic factors for outcome of gastroenteropancreatic neuroendocrine tumors (GEP-NETs): results from the National Cancer Registry of Spain (RGETNE). Ann Oncol. 2010 Sep;21(9):1794-803.

17. Martin-Perez E, Capdevila J, Castellano D, Jimenez-Fonseca P, Salazar R, Beguiristain-Gomez A, et al. Prognostic factors and long-term outcome of pancreatic neuroendocrine neoplasms: Ki-67 index shows a greater impact on survival than disease stage. The large experience of the Spanish National Tumor Registry (RGETNE). Neuroendocrinology. 2013;98(2):156-68.

18. Solis-Hernandez MP, del Valle AF, Carmona-Bayonas A, Garcia-Carbonero R, Custodio A, Benavent M, et al. Evaluating radiological response in pancreatic neuroendocrine tumours treated with sunitinib: comparison of Choi versus RECIST criteria (CRIPNET_GETNE1504 study). Br J Cancer. 2019;121(7):537-44.

19. Eisenhauer EA, Therasse P, Bogaerts J, Schwartz LH, Sargent D, Ford R, et al. New response evaluation criteria in solid tumours: revised RECIST guideline (version 1.1). Eur J Cancer. 2009 Jan;45(2):228-47.

20. Jernman J, Välimäki MJ, Louhimo J, Haglund C, Arola J. The novel WHO 2010 classification for gastrointestinal neuroendocrine tumours correlates well with the metastatic potential of rectal neuroendocrine tumours. Neuroendocrinology. 2012;95(4):317-24.

21. Van de Schoot R, Kaplan D, Denissen J, Asendorpf JB, Neyer FJ, Van Aken MAG. A gentle introduction to Bayesian analysis: Applications to developmental research. Child Dev. 2014;85(3):842-60.

22. Wijeysundera DN, Austin PC, Hux JE, Beattie WS, Laupacis A. Bayesian statistical inference enhances the interpretation of contemporary randomized controlled trials. J Clin Epidemiol. 2009;62(1):13-21.

23. Lewis RJ, Angus DC. Time for clinicians to embrace their inner Bayesian?: reanalysis of results of a clinical trial of extracorporeal membrane oxygenation. Jama. 2018;320(21):2208-10.

24. Adamina M, Tomlinson G, Guller U. Bayesian statistics in oncology: a guide for the clinical investigator. 
Cancer. 2009;115(23):5371-81.

25. Bland JM, Altman DG. Bayesians and frequentists. Br Med J. 1998;317(7166):1151-60.

26. Bürkner P-C. brms: An R package for Bayesian multilevel models using Stan. J Stat Softw. 2017;80(1):1-28.

27. Buuren S van, Groothuis-Oudshoorn K. mice: Multivariate imputation by chained equations in R. J Stat Softw. 2010;1-68.

28. Gabry J, Goodrich B. rstanarm: Bayesian applied regression modeling via Stan. R Packag version. 2016;2(1).

29. Plotly R Open Source Graphing Library [Internet]. [cited 2019 Dec 1]. Available from: https://plot.ly/r/

30. Caplin ME, Pavel M, Ćwikła JB, Phan AT, Raderer M, Sedláčková E, et al. Anti-tumour effects of lanreotide for pancreatic and intestinal neuroendocrine tumours: the CLARINET open-label extension study. Endocr Relat Cancer [Internet]. 2016 Mar;23(3):191-9. Available from: http://www.ncbi.nlm.nih.gov/pubmed/26743120

31. Phan AT, Pavel M, Caplin M, Wolin EM, Mirakhur, Massien, Liyanage N, Pittman RP. Long-Term Efficacy and Safety with Lanreotide Autogel/Depot (LAN) from CLARINET and Open-Label Extension (OLE) Studies. In: ENETS conference. 2020.

32. Wolin EM, Pavel M, Cwikla JB, Phan AT, Raderer M, Sedlackova E, et al. Final progression-free survival (PFS) analyses for lanreotide autogel/depot $120 \mathrm{mg}$ in metastatic enteropancreatic neuroendocrine tumors (NETs): The CLARINET extension study. J Clin Oncol 35, no 15_suppl (May 20 2017).

33. Laskaratos F-M, Walker M, Naik K, Maragkoudakis E, Oikonomopoulos N, Grant L, et al. Predictive factors of antiproliferative activity of octreotide LAR as first-line therapy for advanced neuroendocrine tumours. $\mathrm{Br} \mathrm{J}$ Cancer. 2016;115(11):1321.

34. Rinke A, Wittenberg M, Schade-Brittinger C, Aminossadati B, Ronicke E, Gress TM, et al. Placebo-controlled, double-blind, prospective, randomized study on the effect of octreotide LAR in the control of tumor growth in patients with metastatic neuroendocrine midgut tumors (PROMID): results of long-term survival. Neuroendocrinology. 2017;104(1):26-32.

35. Bruns C, Raulf F, Hoyer D, Schloos J, Lübbert H, Weckbecker G. Binding properties of somatostatin receptor subtypes. Metabolism. 1996;45:17-20.

36. Tutuncu Y, Berker D, Isik S, Ozuguz U, Akbaba G, Kucukler FK, et al. Comparison of octreotide LAR and lanreotide autogel as post-operative medical treatment in acromegaly. Pituitary [Internet]. 2012 Sep;15(3):398404. Available from: https://www.ncbi.nlm.nih.gov/pubmed/21863263

37. Auriemma RS, Pivonello R, Galdiero M, De Martino MC, De Leo M, Vitale G, et al. Octreotide-LAR vs lanreotide-SR as first-line therapy for acromegaly: a retrospective, comparative, head-to-head study. J Endocrinol Invest [Internet]. 2008 Nov;31(11):956-65. Available from:

https://www.ncbi.nlm.nih.gov/pubmed/19169050

38. Andries M, Glintborg D, Kvistborg A, Hagen C, Andersen M. A 12-month randomized crossover study on the effects of lanreotide Autogel and octreotide long-acting repeatable on GH and IGF-I in patients with acromegaly. Clin Endocrinol (Oxf) [Internet]. 2007/10/17. 2008 Mar;68(3):473-80. Available from: https://www.ncbi.nlm.nih.gov/pubmed/17941902

39. van Thiel SW, Romijn JA, Biermasz NR, Ballieux BEPM, Frölich M, Smit JWA, et al. Octreotide long-acting repeatable and lanreotide Autogel are equally effective in controlling growth hormone secretion in acromegalic patients. Eur J Endocrinol [Internet]. 2004 Apr;150(4):489-95. Available from:

https://www.ncbi.nlm.nih.gov/pubmed/15080778

40. Razzore P, Colao A, Baldelli R, Gaia D, Marzullo P, Ferretti E, et al. Comparison of six months therapy with octreotide versus lanreotide in acromegalic patients: a retrospective study. Clin Endocrinol (Oxf) [Internet]. 1999 Aug;51(2):159-64. Available from: https://www.ncbi.nlm.nih.gov/pubmed/10468985

41. Modlin IM, Pavel M, Kidd M, Gustafsson BI. Review article: somatostatin analogues in the treatment of gastroenteropancreatic neuroendocrine (carcinoid) tumours. Aliment Pharmacol Ther [Internet]. 2010 Jan 15 [cited 2015 Nov 3];31(2):169-88. Available from: http://www.ncbi.nlm.nih.gov/pubmed/19845567

42. Rubin J, Ajani J, Schirmer W, Venook AP, Bukowski R, Pommier R, et al. Octreotide acetate long-acting formulation versus open-label subcutaneous octreotide acetate in malignant carcinoid syndrome. $\mathrm{J}$ Clin Oncol Off J Am Soc Clin Oncol [Internet]. 1999;17(2):600-6. Available from: http://www.ncbi.nlm.nih.gov/pubmed/10080605

43. Asnacios A, Courbon F, Rochaix P, Bauvin E, Cances-Lauwers V, Susini C, et al. Indium-111-pentetreotide scintigraphy and somatostatin receptor subtype 2 expression: new prognostic factors for malignant welldifferentiated endocrine tumors. J Clin Oncol [Internet]. 2008 Feb 20 [cited 2015 Dec 25];26(6):963-70. Available from: http://www.ncbi.nlm.nih.gov/pubmed/18281671

44. Wang Y, Wang W, Jin K, Fang C, Lin Y, Xue L, et al. Somatostatin receptor expression indicates improved prognosis in gastroenteropancreatic neuroendocrine neoplasm, and octreotide long-acting release is effective and safe in Chinese patients with advanced gastroenteropancreatic neuroendocrine tumors. Oncol Lett. 2017;13(3):1165-74.

45. Srirajaskanthan R, Watkins J, Marelli L, Khan K, Caplin ME. Expression of somatostatin and dopamine 2 receptors in neuroendocrine tumours and the potential role for new biotherapies. Neuroendocrinology [Internet]. 2009/03/23. 2009;89(3):308-14. Available from: https://www.ncbi.nlm.nih.gov/pubmed/19307732

46. Rodrigues M, Gabriel M, Heute D, Putzer D, Griesmacher A, Virgolini I. Concordance between results of somatostatin receptor scintigraphy with $111 \mathrm{ln}$-DOTA-DPhe 1-Tyr 3-octreotide and chromogranin A assay in patients with neuroendocrine tumours. Eur J Nucl Med Mol Imaging [Internet]. 2008/04/19. 2008 Oct;35(10):1796-802. Available from: https://www.ncbi.nlm.nih.gov/pubmed/18425512

47. Caron P, Bex M, Cullen DR, Feldt-Rasmussen U, Pico Alfonso AM, Pynka S, et al. One-year follow-up of patients with acromegaly treated with fixed or titrated doses of lanreotide Autogel®. Clin Endocrinol (Oxf). 2004;60(6):734-40.

48. Chanson P, Borson-Chazot F, Kuhn J, Blumberg J, Maisonobe P, Delemer B, et al. Control of IGF-I levels with 
titrated dosing of lanreotide Autogel over 48 weeks in patients with acromegaly. Clin Endocrinol (Oxf). 2008;69(2):299-305.

49. Saif MW, Fu J, Smith MH, Weinstein B, Relias V, Daly KP. Treatment with Lanreotide Depot Following Octreotide Long-Acting Release Among Patients with Gastroenteropancreatic Neuroendocrine Tumors. J Pancreat cancer. 2018;4(1):64-71.

50. Ni S-J, Sheng W-Q, Du X. Pathologic research update of colorectal neuroendocrine tumors. World J Gastroenterol WJG. 2010;16(14):1713.

51. Kim HS, Lee HS, Kim WH. Clinical significance of protein expression of cyclooxygenase-2 and somatostatin receptors in gastroenteropancreatic neuroendocrine tumors. Cancer Res Treat Off J Korean Cancer Assoc. 2011;43(3):181.

52. Caplin ME, Pavel M, Cwikła JB, Phan AT, Raderer M, Sedláčková E, et al. Lanreotide in metastatic enteropancreatic neuroendocrine tumors. N Engl J Med. 2014 Jul 17;371(3):224-33.

53. Imaoka H, Sasaki M, Takahashi H, Hashimoto Y, Ohno I, Mitsunaga S, et al. Progression-free survival as a surrogate endpoint in advanced neuroendocrine neoplasms. Endocr Relat Cancer. 2017;24(9):475-83.

54. Huynh L, Cai B, Cheng M, Lax A, Lejeune D, Duh MS, et al. Analysis of Real-World Treatment Patterns, Healthcare Resource Utilization, and Costs Between Octreotide and Lanreotide Among Patients With Neuroendocrine Tumors. Pancreas [Internet]. 2019 Oct;48(9):1126-35. Available from: https://www.ncbi.nlm.nih.gov/pubmed/31593022

55. Ayyagari R, Neary M, Li S, Rokito A, Yang H, Xie J, et al. Comparing the Cost of Treatment with Octreotide Long-Acting Release versus Lanreotide in Patients with Metastatic Gastrointestinal Neuroendocrine Tumors. Am Heal drug benefits [Internet]. $2017 \mathrm{Nov} ; 10(8): 408-15$. Available from: https://www.ncbi.nlm.nih.gov/pubmed/29263774

56. Sleight P. Debate: Subgroup analyses in clinical trials: fun to look at-but don't believe them! Trials. 2000;1(1):25. 


\section{Figure Legends}

Table 1. Baseline patient characteristics.

Abbreviations: ULN, upper limit of normal; LAR, long-acting release; ND, not documented; SSA, somatostatin analogue. * Defined as radiotracer uptake in the primary tumor or metastases. Proliferative doses are $120 \mathrm{mg}$ for lanreotide and $30 \mathrm{mg}$ each for octreotide; intermediate doses are $90 \mathrm{mg}$ and $20 \mathrm{mg}$ respectively; low doses are $60 \mathrm{mg}$ and $10 \mathrm{mg}$, respectively.

Table 2. Most common adverse events.

Note: toxicity was evaluated according to $\mathrm{NCl}-\mathrm{CTC}$ criteria v3.0.

Table 3. Evaluation of effect-modifying factors.

Abbreviations: Crl, credible interval; HR, hazard ratio; SD, stable disease; ULN, upper limit of normal. The estimates correspond to subgroup analyses (interactions). The full Bayesian Cox model (multivariable) has been used by adding one interaction at a time.

Fig. 1. Kaplan-Meier curves for PFS and OS. Abbreviations: PFS= progression-free survival, OS= overall survival.

Fig. 2. Posterior probability mass included in the Region of Practical Equivalence. Note: Continuous variables (Ki67\%, year, NLR) were modelled through natural splines. A spline is a piecewise polynomial function that allows the evaluation of non-linear associations. Spline fits contain several coefficients labeled according to the number of knots; the overall effect is built by linear combinations of these estimates. Abbreviations: NLR = neutrophil-to-lymphocyte ratio, ULN $=$ upper limit of normal.

Fig. 3. Cox proportional hazards model for PFS (frequentist approach). Note: interquartile range effects were used for continuous variables. Abbreviations: $\mathrm{Cl}=$ confidence interval, $\mathrm{NLR}=$ neutrophil to lymphocyte ratio, $\mathrm{SD}=$ stable disease, $\mathrm{UK}=$ unknown, $\mathrm{ALP}=$ alkaline phosphatase, ULN=upper limit of normal.

Fig. 4. Kaplan-Meier curves for progression-free survival according to primary tumor site.

Fig. 5. Kaplan-Meier curves for overall survival according to primary tumor site.

Fig. 6. 6A Therapeutic effect of lanreotide autogel on PFS over time. 6B Effect of time on PFS 
Table 1. Baseline patient characteristics.

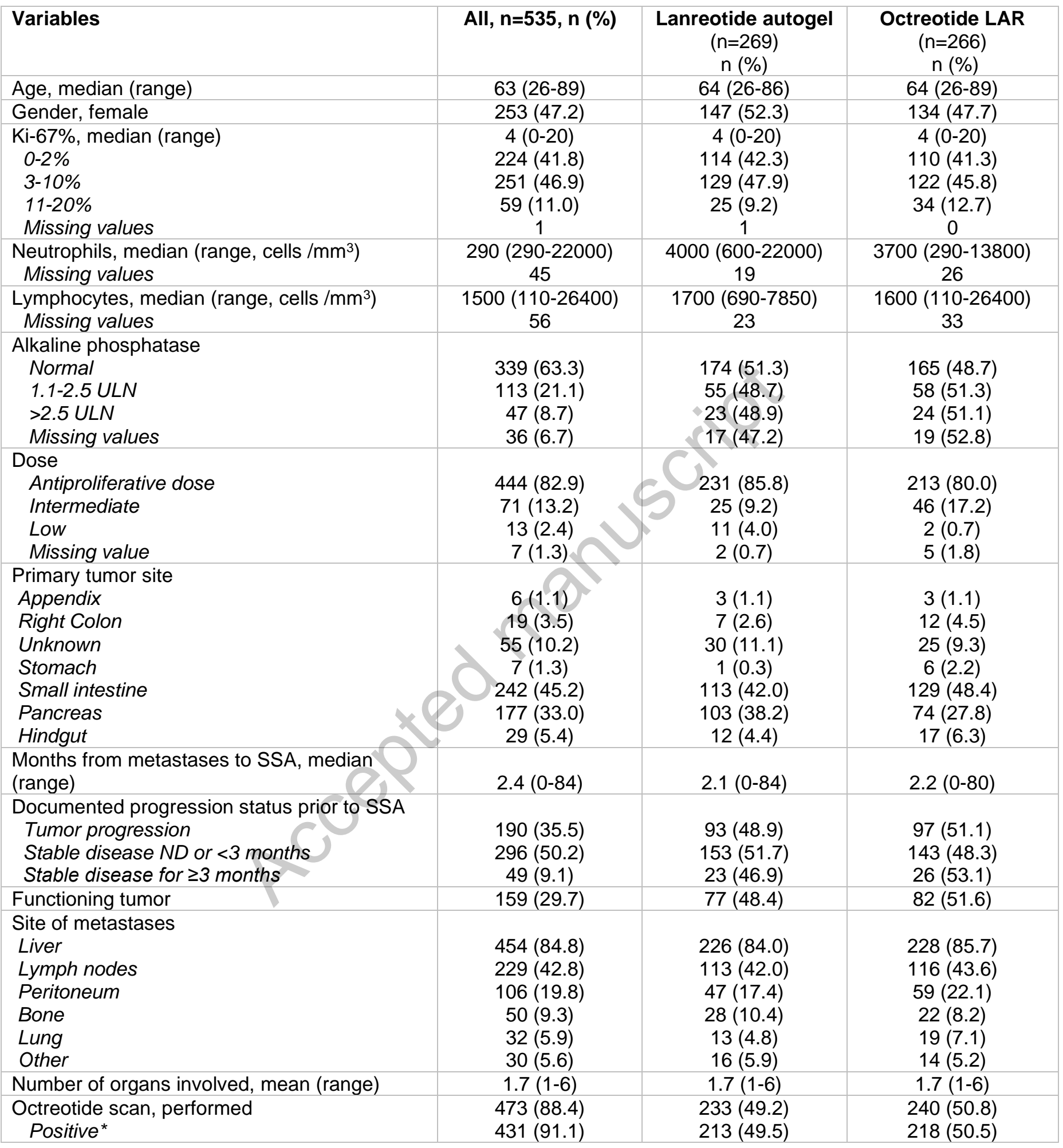


Table 2. Most common adverse events

\begin{tabular}{|l|c|c|c|c|}
\hline \multirow{2}{*}{ Adverse event } & \multicolumn{2}{|c|}{$\begin{array}{c}\text { Lanreotide autogel, \% } \\
\text { Any grade }\end{array}$} & \multicolumn{2}{c|}{ Octreotide LAR, \% } \\
\hline Cholelithiasis & 7.2 & 1.3 & 10.2 & Any grade \\
\hline Hematology & 6.3 & 0.9 & 4.1 & 0 \\
\hline Malabsorption & 2.7 & 0 & 1.8 & 0 \\
\hline Cardiac & 0.9 & 0.4 & 1.3 & 0.4 \\
\hline Liver & 6.3 & 1.3 & 8.8 & 0 \\
\hline Diarrhea & 20.2 & 0 & 20.0 & 0 \\
\hline Emesis & 3.1 & 0 & 2.7 & 0 \\
\hline Asthenia & 18.0 & 0.4 & 21.8 & 0.4 \\
\hline Other & 7.2 & 1.3 & 6.5 & 0.9 \\
\hline
\end{tabular}


Table 3. Evaluation of effect-modifying factors.

\begin{tabular}{|l|c|c|}
\hline Variables & $\begin{array}{c}\text { Hazard ratio } \\
\mathbf{( 9 5 \% , ~ C r l ) ~}\end{array}$ & $\begin{array}{c}\text { Posterior probability } \\
\text { HR }<\mathbf{0 . 7 0}\end{array}$ \\
\hline Tumor progression & $1.07(0.76-1.49)$ & $1 \%$ \\
\hline SD not documented or <3 months & $0.84(0.62-1.13)$ & $10 \%$ \\
\hline SD $\geq 3$ months & $0.55(0.29-1.05)$ & $76 \%$ \\
\hline Tumor or endocrine-related symptoms & $1.00(0.81-1.23)$ & 0 \\
\hline No symptoms & $0.65(0.41-1.03)$ & $60 \%$ \\
\hline Peritoneal metastases: yes & $1.37(0.89-2.11)$ & $1 \%$ \\
\hline Peritoneal metastases: no & $0.83(0.67-1.02)$ & $9 \%$ \\
\hline Bone metastases: yes & $1.00(0.57-1.75)$ & $15 \%$ \\
\hline Bone metastases: no & $0.89(0.73-1.09)$ & $2 \%$ \\
\hline Unknown origin & $0.71(0.41-1.25)$ & $47 \%$ \\
\hline Midgut & $1.01(0.73-1.38)$ & $2 \%$ \\
\hline Foregut & $0.91(0.66-1.25)$ & $6 \%$ \\
\hline Hindgut & $0.75(0.48-0.18)$ & $37 \%$ \\
\hline Alkaline phosphatase $>2.5$ ULN & $1.55(0.91-2.66)$ & $1 \%$ \\
\hline Alkaline phosphatase 1.1-2.5 ULN & $0.74(0.52-1.07)$ & $39 \%$ \\
\hline Alkaline phosphatase normal & $0.88(0.69-1.13)$ & $5 \%$ \\
\hline No liver metastases & $1.17(0.72-1.91)$ & $4 \%$ \\
\hline Liver involvement $>50 \%$ & $0.73(0.45-1.17)$ & $42 \%$ \\
\hline Liver involvement 25-50\% & $0.97(0.68-1.38)$ & $3 \%$ \\
\hline Liver involvement 0-24\% & $0.85(0.59-1.21)$ & $14 \%$ \\
\hline & & \\
\hline
\end{tabular}




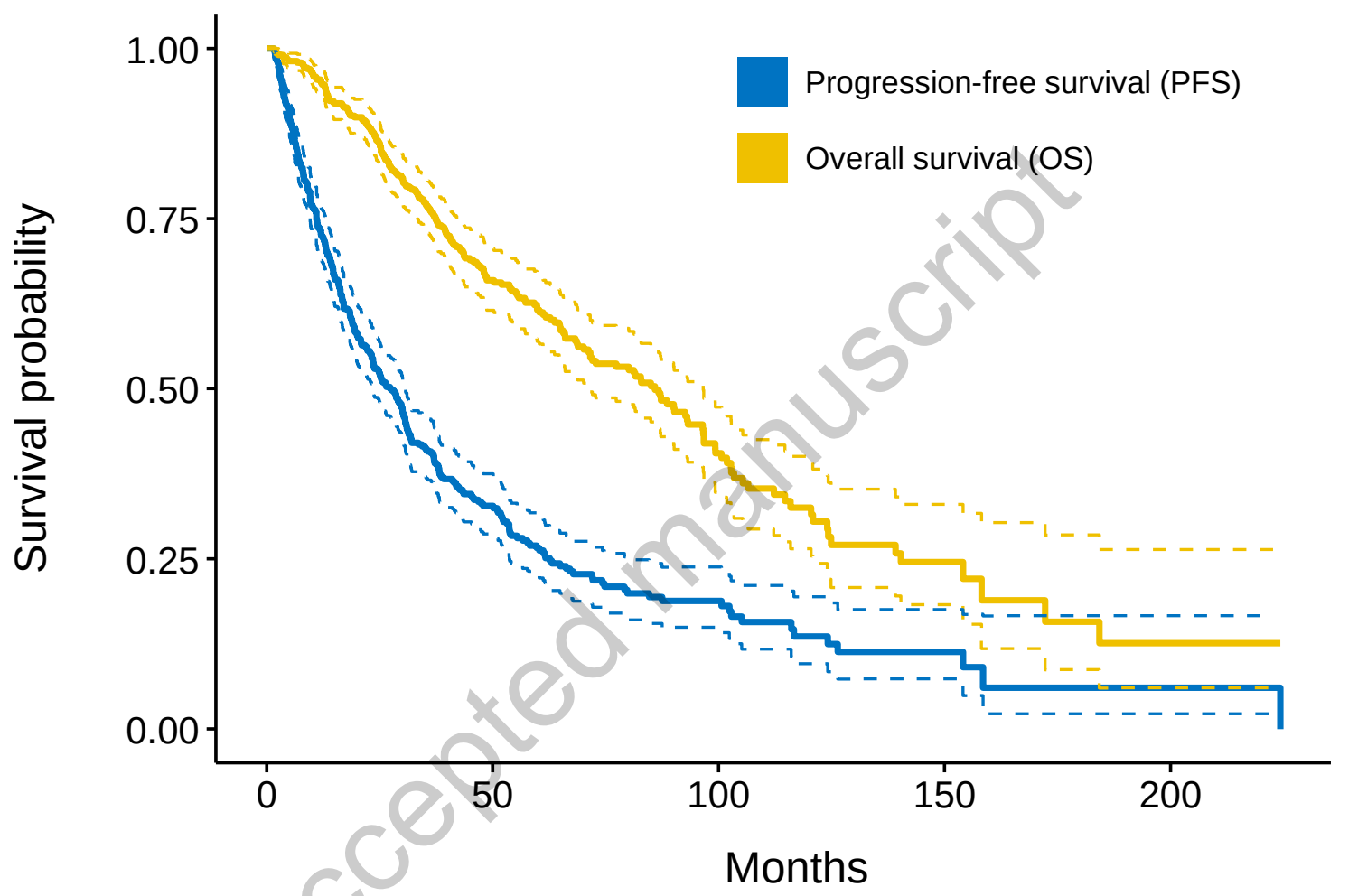

Number at risk

PFS: $\quad 535$

101

26

8

2

OS: 535

210

58

14

2 


\section{Region of Practical Equivalence (ROPE)}

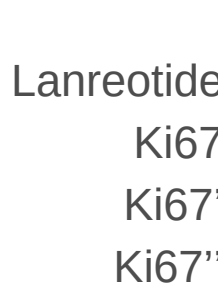

Stable disease for $>3$ months

Tumor progression

Foregut

Small intestine

Unknown origin

Peritoneal metastases

Hepatic tumor burden 1-24\%

Hepatic tumor burden 25-50\%

No liver metastases

Asymptomatic

Bone metastases

Year

Year'

Year"

NLR

NLR'

NLR'

Antiproliferative dose

AP 1.1-2.5 ULN

AP $>2.5$ ULN

$-$

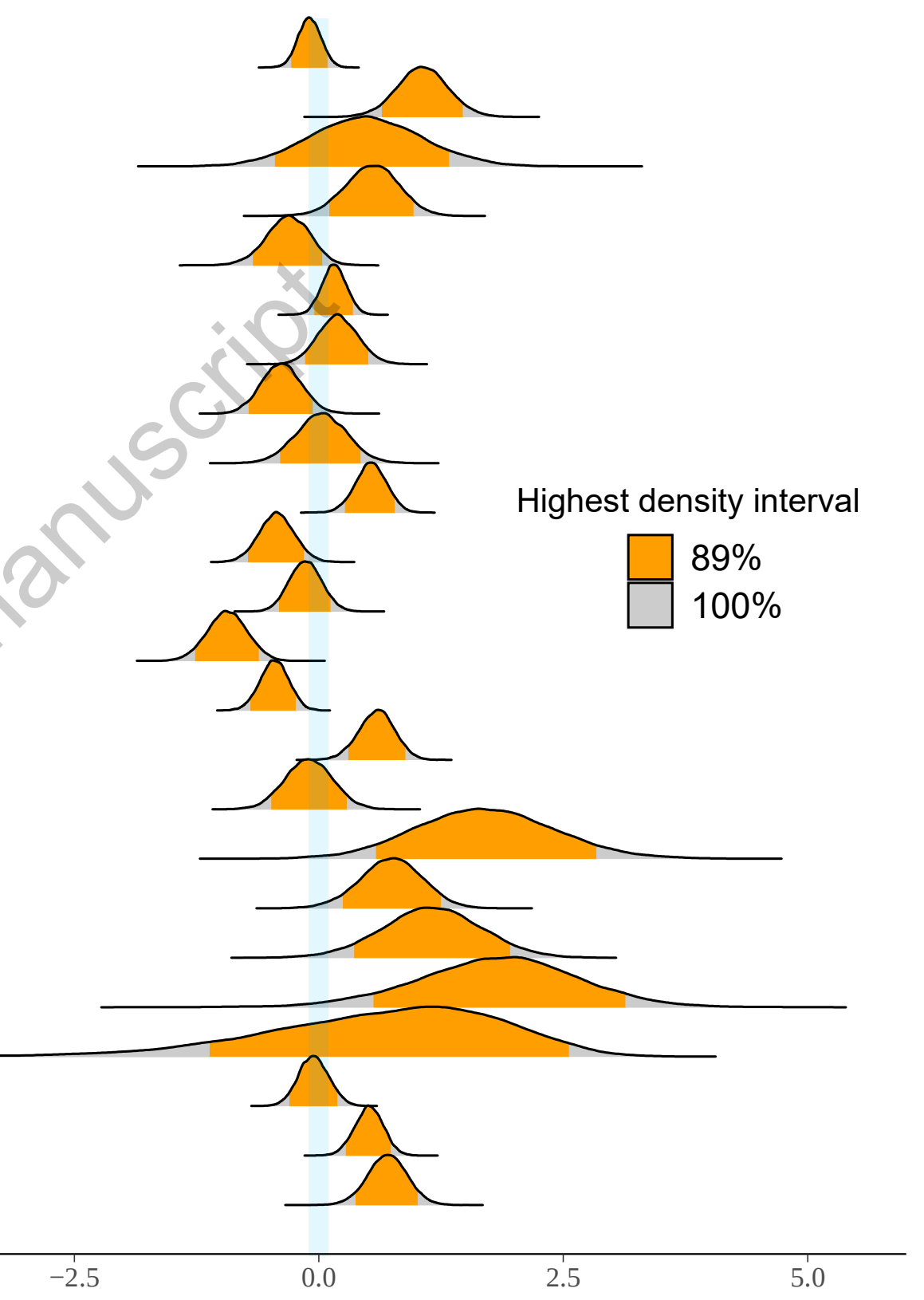

Posterior densities for the log hazard ratio 


\section{Hazard Ratio $(66,95,99 \% \mathrm{Cl})$}

Lanreotide autogel

$\mathrm{Ki} 67 \%-8: 2$

Peritoneal metastases

Asymptomatic Bone metastases

Year - 2015:2009

NLR - 3.3:1.6

Full dose

SD >3 months Progressive disease Hindgut vs midgut Foregut vs midgut UK vs midgut

Liver involvement, $>50 \%$ vs $1-24 \%$ Liver involvement, $25-50 \%$ vs $1-24 \%$

Liver involvement, no vs $1-24 \%$

AP 1.1-2.5 ULN AP $>2.5$ ULN

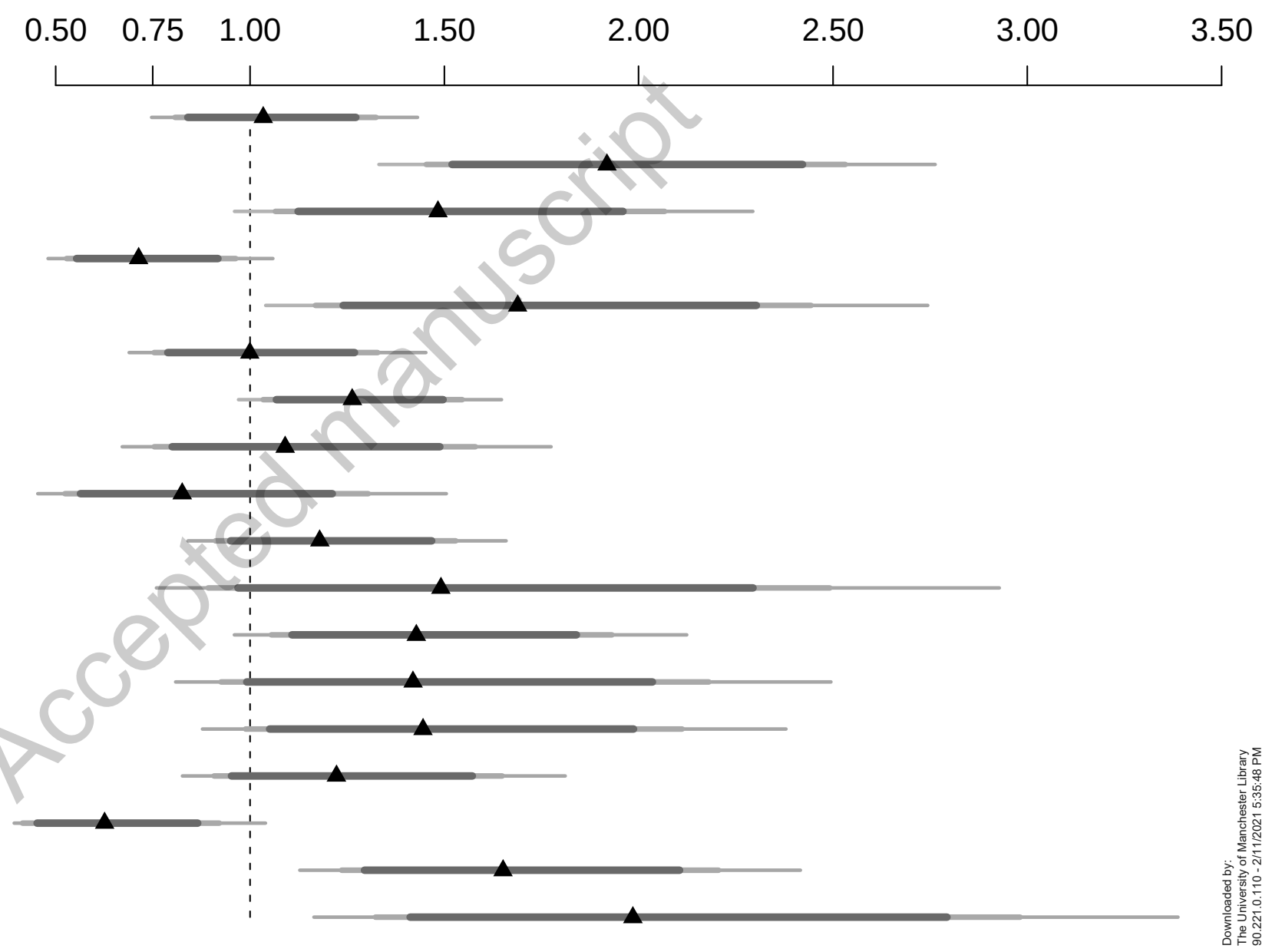




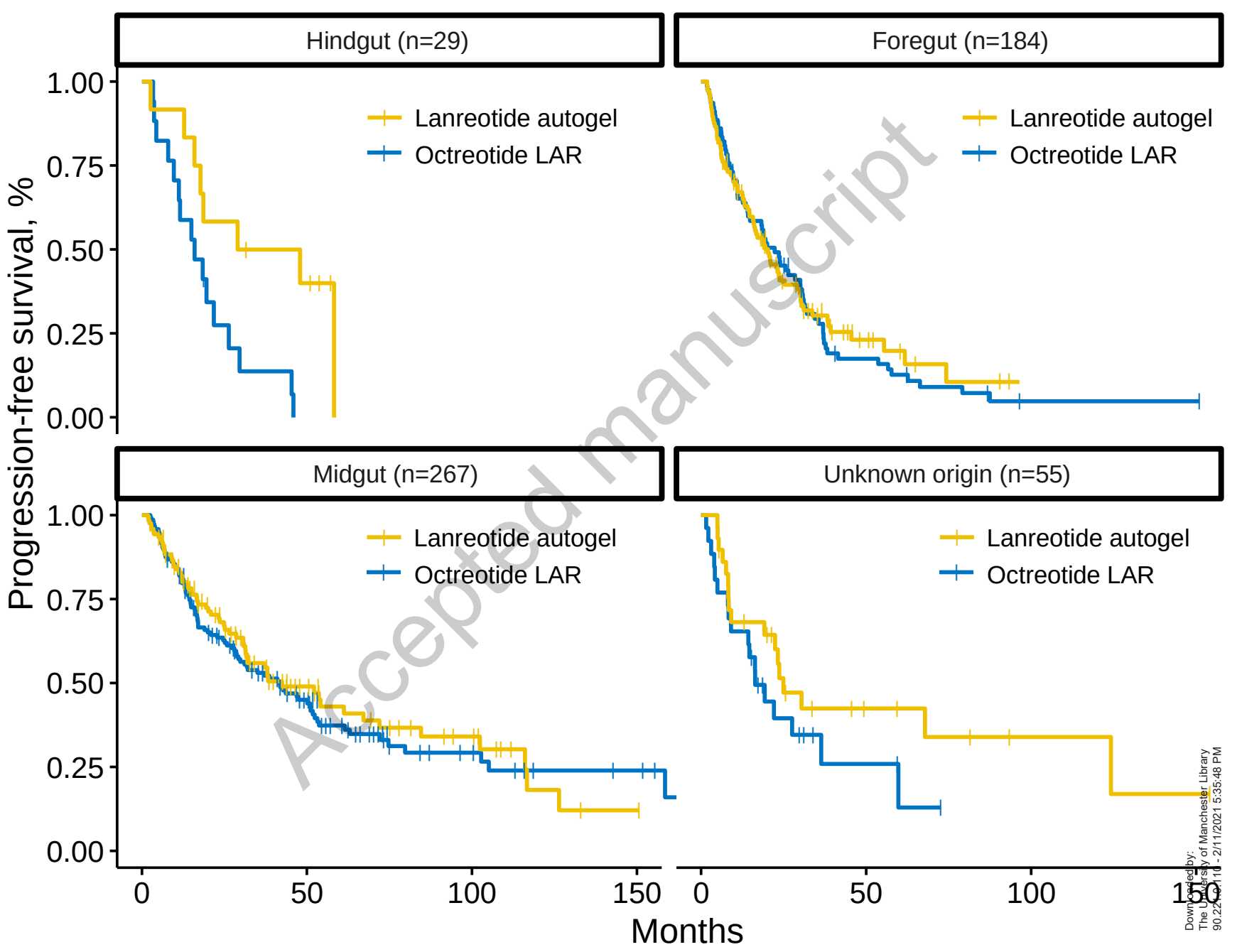




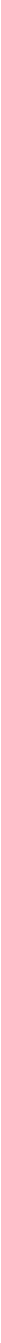



A
B
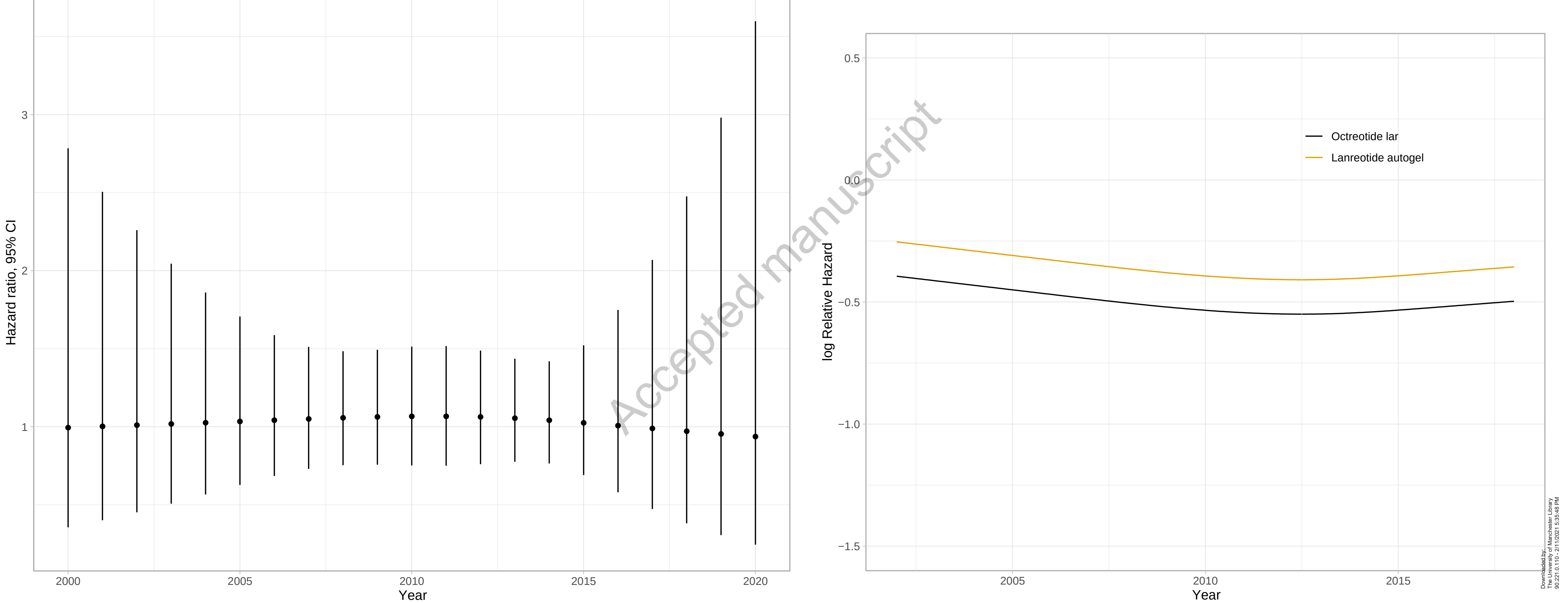
Annex Figure 1. Flow-chart

Patients assessed ( $n=3971)$

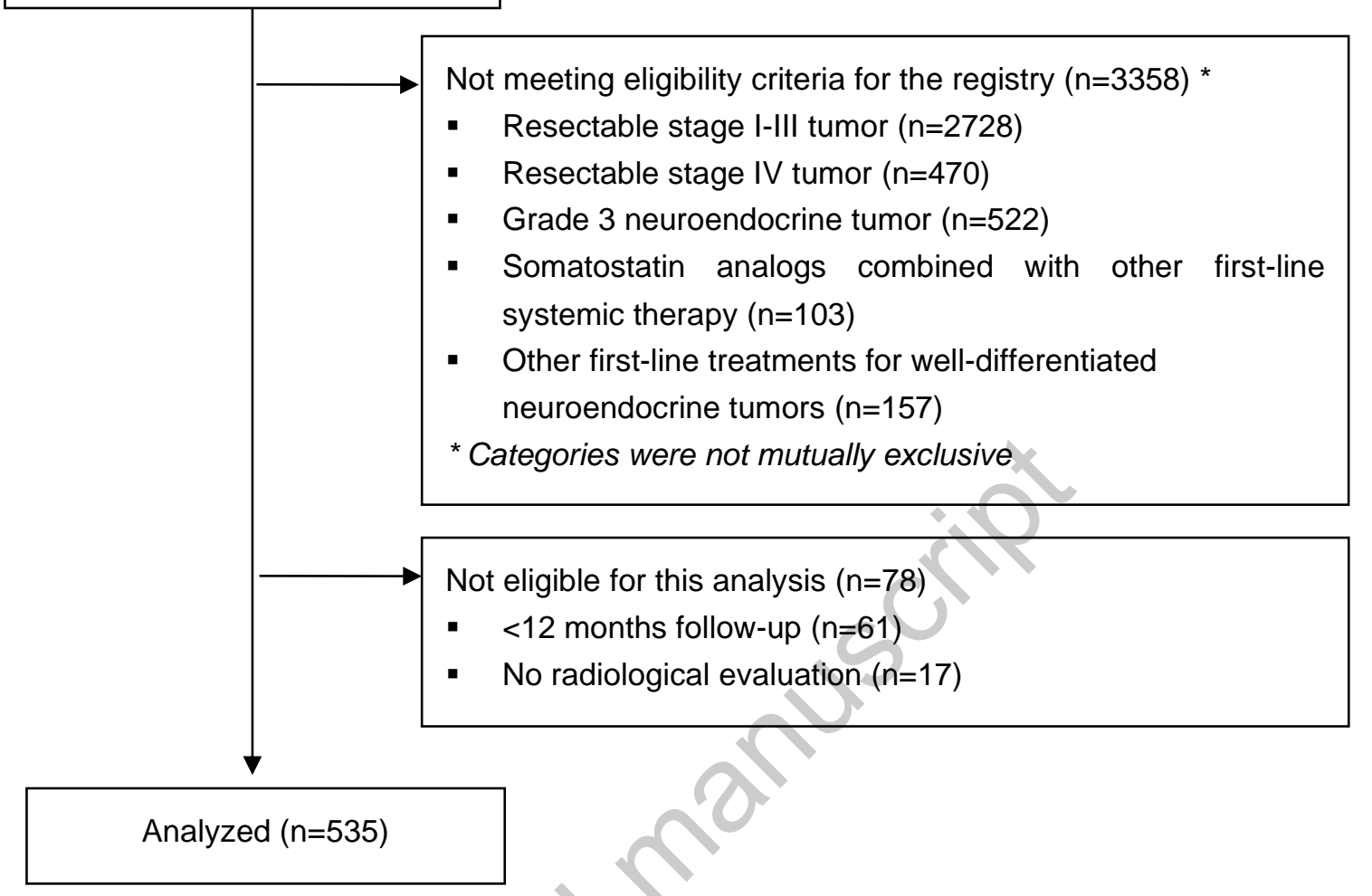



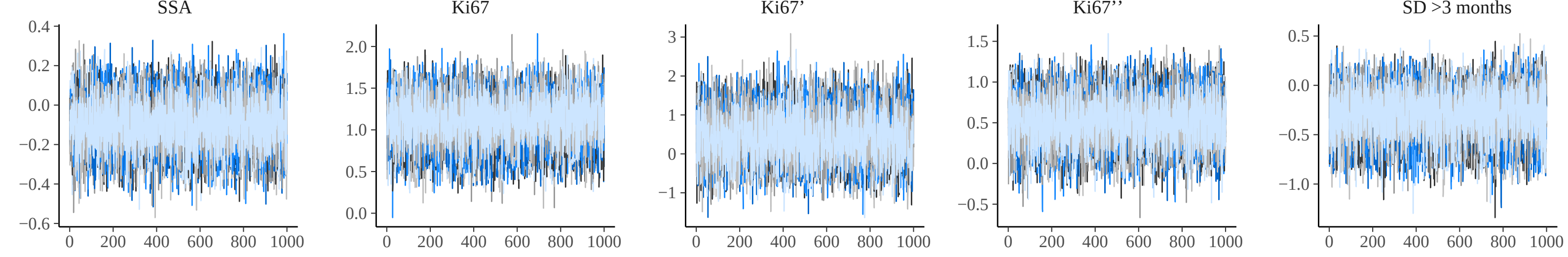

PD
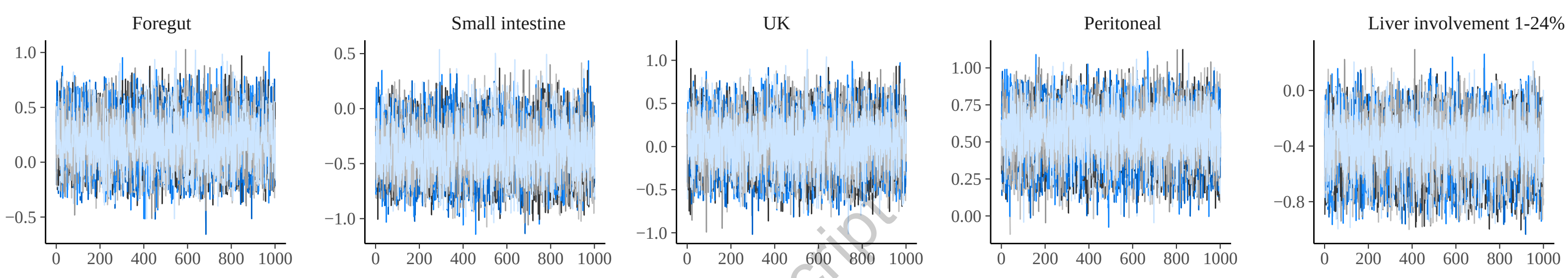

Chain

- 1

$-2$

$-3$ Bone

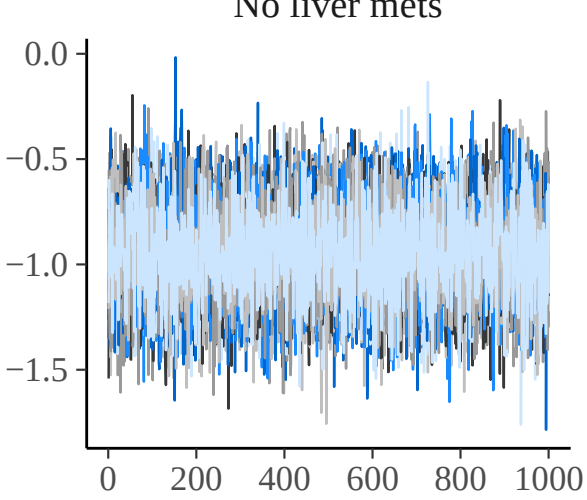

No symptoms
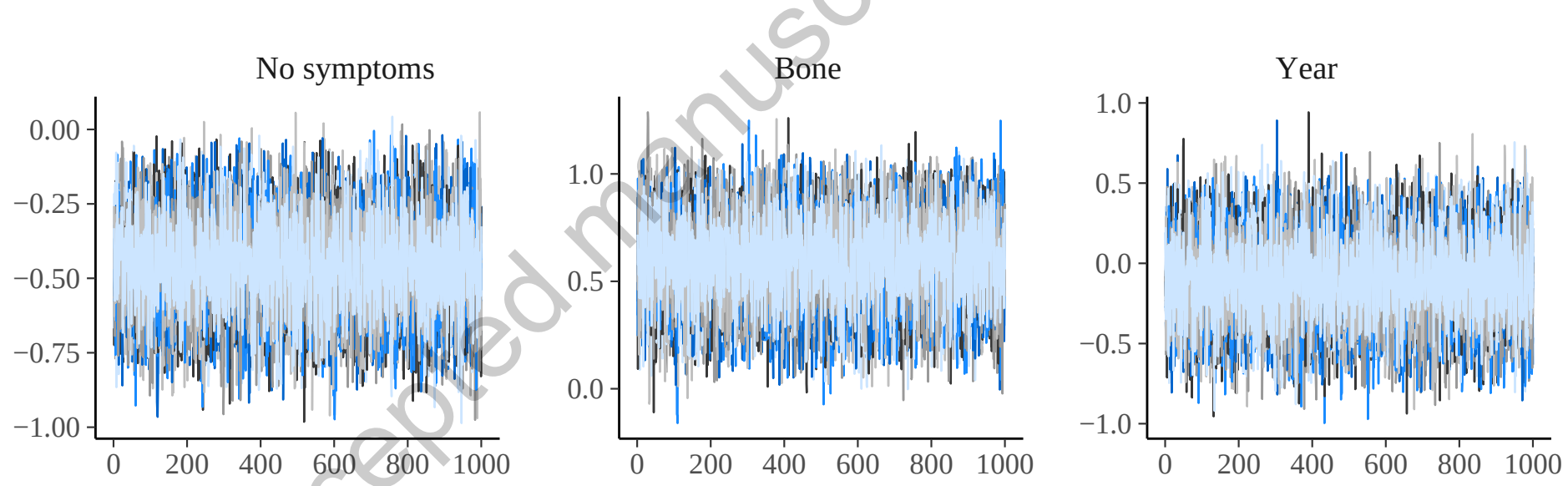

NLR'
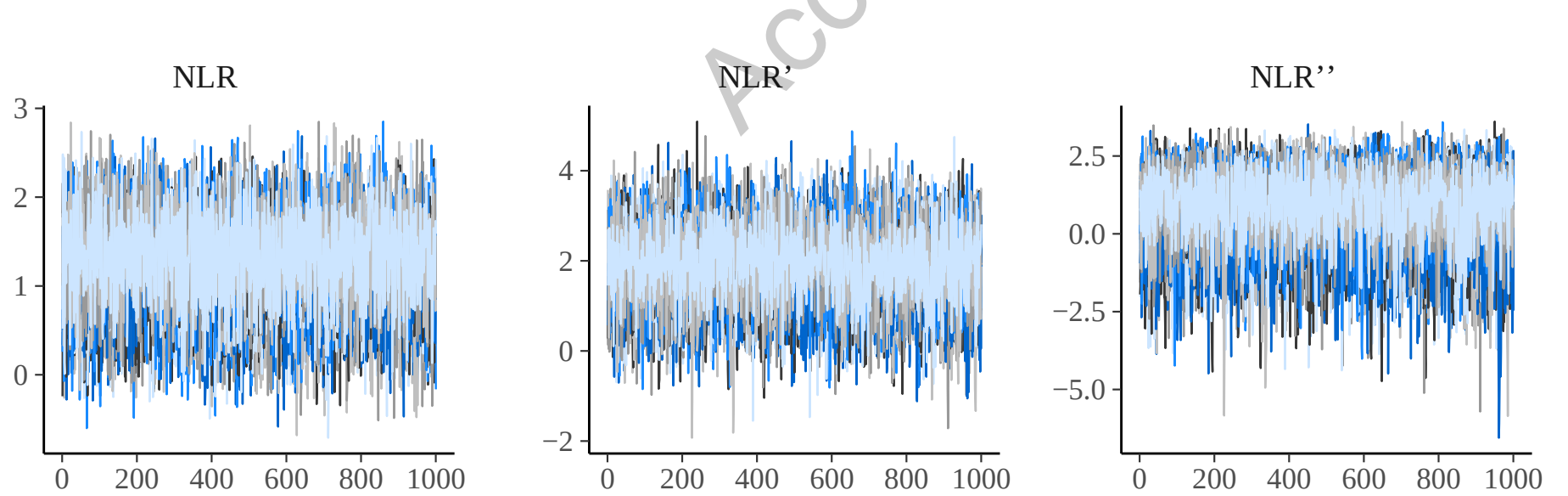

Doses
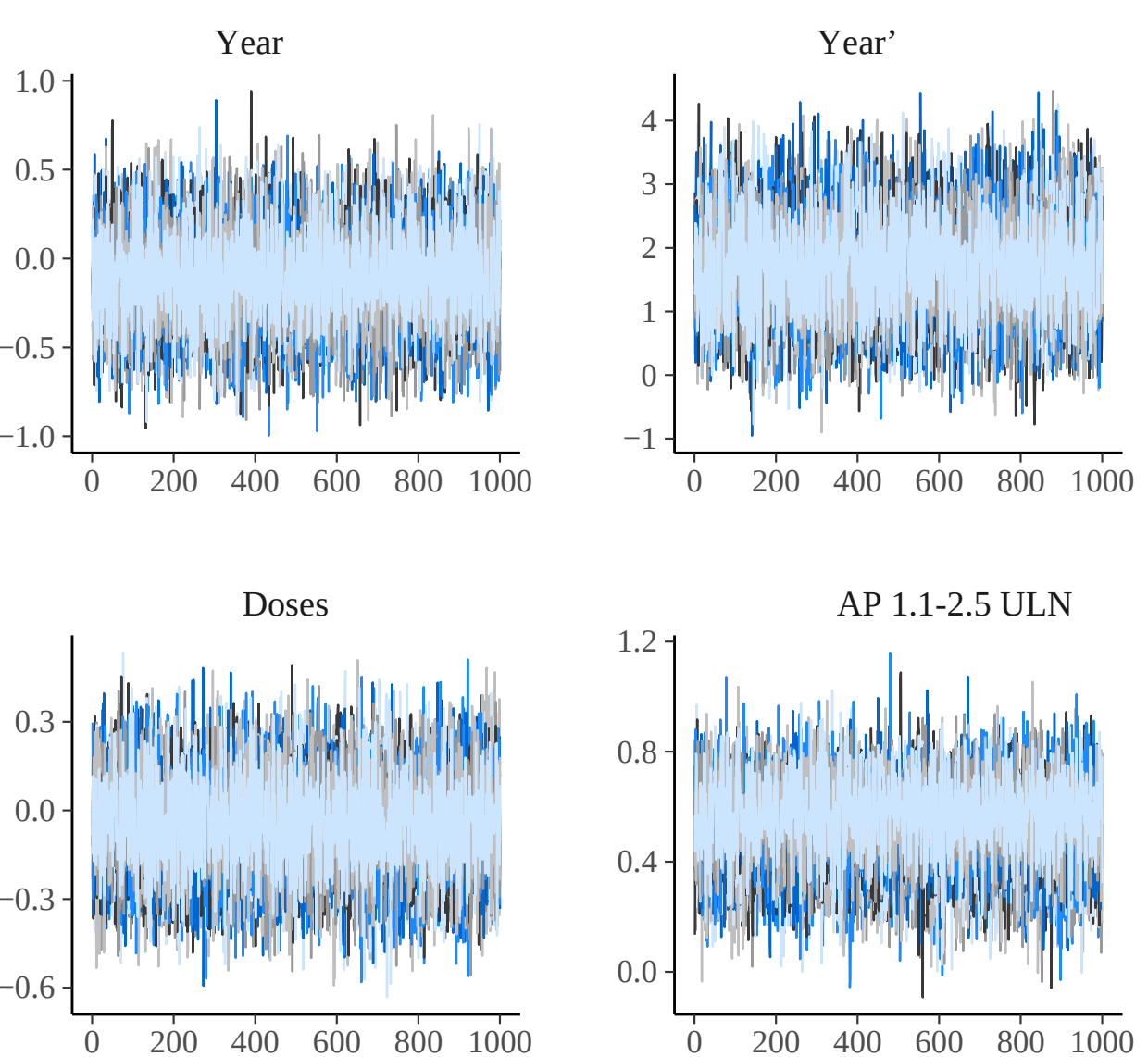

- 5

$-6$

$-7$

7
$-\quad 8$
-9

10

- 10

11
-12
-13

14

$-15$

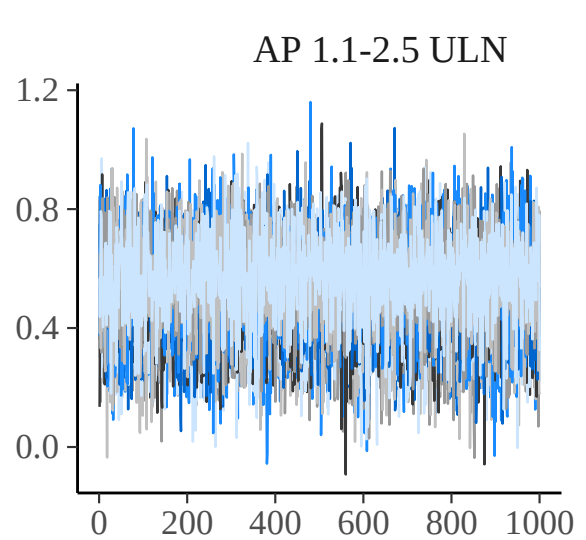

sbhaz[1]
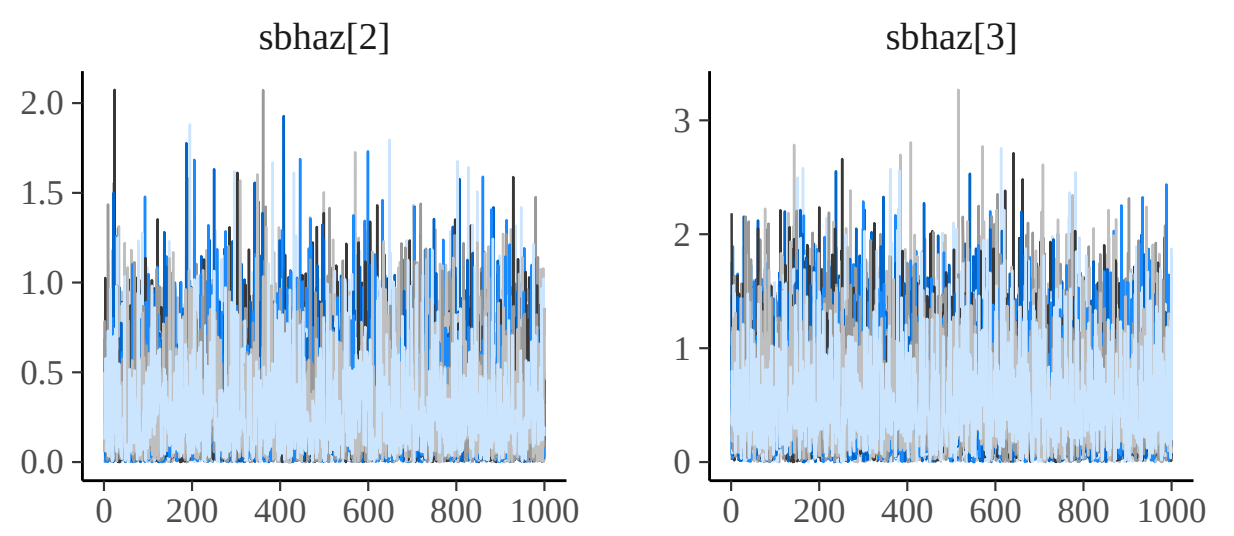

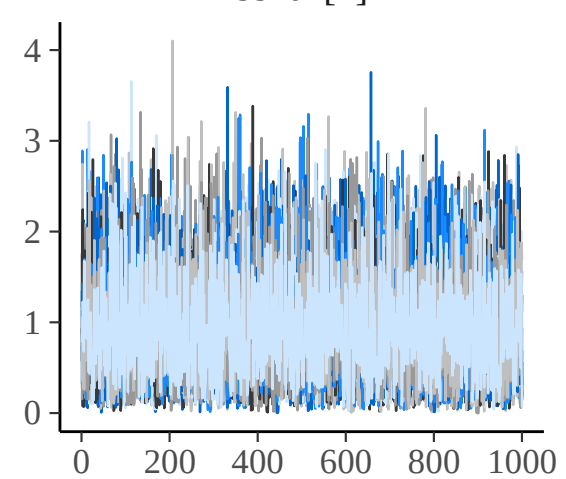

lp

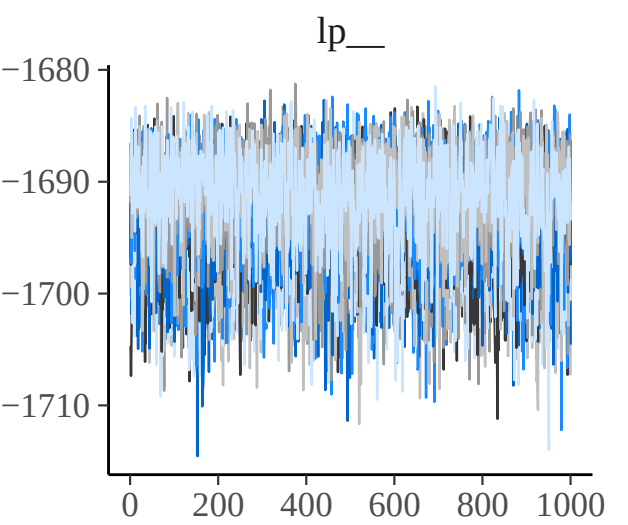

